\title{
AS FACES INSÓLITAS DA IARA
}

\author{
THE UNUSUAL FACES OF IARA
}

Daniele Mendes Sousa ${ }^{1}$

ORCID: https://orcid.org/0000-0003-4994-9260

Danielle da Silva Rodrigues ${ }^{2}$

ORCID: https://orcid.org/0000-0001-8556-6940

Suellen Cordovil da Silva ${ }^{3}$

ORCID: https://orcid.org/0000-0001-7421-0922

Resumo: Este artigo tem como objetivo analisar a personagem Iara no conto "A Iara do Rio Santana", no livro "Visagens, Assombrações e Encantamentos da Amazônia" (2019), de Walcyr Monteiro (1940-2019). A Iara é uma lenda que faz parte do folclore brasileiro; sendo assim, estudaremos sob uma perspectiva do gótico, insólito ficcional e o fantástico como modo. Além disso, buscamos embasamento nos estudos de Flávio Garcia (2012), que descreve o insólito como uma categoria ficcional comum a variados gêneros literários. Já para Marisa Gama-Khalil (2019) apud Furtado (2011), o fantástico é entendido como um modo que agrega textos e gêneros heterogêneos por meio de um aspecto em comum: o sobrenatural, integrando o conto de fadas, o gótico, o maravilhoso, o estranho, a ficção científica e outras modalidades. Para complementar nossa base teórica, serão abordadas as ideias de Noël Carroll, especialmente a obra "The philosophy of horror" (1990). Também serão contempladas as obras "Folk-lore Brésilien" (1889), de Frederico José de Santa-Anna Nery e "Lendas Brasileiras" (2015) e "Geografia dos Mitos Brasileiros" (2012), de Câmara Cascudo. Dessa forma, pretendemos explorar a pluralidade que envolve as narrativas dessa personagem pelo viés gótico. Iara é um ser insólito que habita os rios amazônicos, carregando uma assustadora maldição: seu canto hipnotizante e sua beleza mortal a transformam em uma ceifadora de homens, atraindo-os para o fundo das águas.

Palavras-chave: Iara. A Iara do Rio Santana. Walcyr Monteiro. Gótico. Insólito.

\footnotetext{
${ }^{1}$ Graduanda em Letras-Inglês na Universidade Federal do Sul e do Sudeste do Pará (UNIFESSPA). Participou do grupo de pesquisa "O Fantástico na Amazônia", coordenado pela Profa Dra Suellen Cordovil da Silva, desenvolvendo o artigo intitulado "As faces insólitas da Iara", o qual foi apresentado em forma de comunicação no $4^{\circ}$ Seminário de Estudos do Gótico realizado pela UFSC. ${ }^{2}$ Graduanda em Letras-Inglês na Universidade Federal do Sul e Sudeste do Pará (UNIFESSPA). Participou do grupo de pesquisa intitulado "O fantástico na Amazônia" entre 18 de março a 13 de novembro de 2021, onde desenvolveu o artigo intitulado "As faces insólitas da Iara" e o apresentou no $4^{\circ}$ Seminário de Estudos do Gótico realizado pelo programa de pós-graduação em literatura da UFSC.

${ }^{3}$ Professora Adjunta de Letras de Língua e Literatura de Língua Inglesa da Universidade Federal do Sul e Sudeste do Pará (Unifesspa). Coordenadora do grupo de pesquisa intitulado "O fantástico na Amazônia".
} 


\begin{abstract}
This article aims to analyze the character Iara in the short story "A Iara do Rio Santana", in the book "Visagens, Assombrações e Encantamentos da Amazônia" (2019), by Walcyr Monteiro (1940-2019). Iara is a legend that is part of Brazilian folklore; therefore, we will study it from the gothic, fictional unusual, and the fantastic as a mode perspective. In addition, we seek support from the studies of Flávio Garcia (2012), who describes the uncommon as a fictional category common to several literary genres. For Marisa Gama-Khalil (2019) apud Furtado (2011), the fantastic is a mode that aggregates heterogeneous texts and genres through a common aspect: the supernatural, integrating the fairy tale, the gothic, the marvelous, the strange, science fiction, and other modalities. To complement our theoretical basis in the ideas of Noël Carroll will be addressed, especially in this work "The philosophy of horror" (1990). We will also contemplate the works "Folk-lore Brésilien" (1889), by Frederico José de Santa-Anna Nery and "Lendas Brasileiras" (2015) and "Geografia dos Mitos Brasileiros" (2012), by Câmara Cascudo. In this way, we intend to explore the plurality that surrounds the narratives of this character through the Gothic bias. Iara is an unusual being that inhabits the Amazon rivers, carrying a scary curse: her mesmerizing song and deadly beauty transform her into a reaper of men, luring them to the bottom of the waters.
\end{abstract}

Keywords: Iara. A Iara do Rio Santana. Walcyr Monteiro. Gothic. Uncommon.

\title{
INTRODUÇÃO
}

O folclore brasileiro é rico em mitos e lendas, agrupando histórias fantásticas que perpetuam a cultura brasileira. O fantástico engloba todas essas histórias que possuem aspectos sobrenaturais. A autora Marisa Gama-Khalil (2019) apud Furtado (2011) afirma que o fantástico é entendido como um modo que agrega textos e gêneros heterogêneos por meio de um aspecto em comum: o sobrenatural, integrando o conto de fadas, o gótico, o maravilhoso, o estranho, a ficção científica e outras modalidades. Desse modo, a lenda da Iara encaixa-se nos estudos do fantástico como modo.

Uma lenda torna-se mutável ao se propagar entre povos, adquirindo características iguais e ao mesmo tempo diferentes, tal como a lenda da Iara, uma personagem plurifacetada do imaginário brasileiro. De acordo com o Dicionário de Folclore Brasileiro (2005) de Câmara Cascudo, uma lenda trata-se de um episódio heroico ou sentimental atrelado ao elemento maravilhoso ou sobre-humano, que é transmitido e preservado ao longo dos anos pela tradição oral, podendo ser localizada no espaço e no tempo. A lenda também preserva as quatro características do conto popular: Antiguidade, Persistência, Anonimato, Oralidade. Apesar do termo Iara (Yara) ou Uiaras ser do idioma tupi, sendo o nome convencional e literário da mãe-d'água, ig-água, iara-senhor, que resulta em senhora das águas, essa 
personagem folclórica descende de uma roupagem europeia e tem feito parte da tradição cultural do Brasil desde os tempos da colonização.

A pluralidade da personagem Iara é apresentada em diferentes regiões, é refletida nas representações que encontramos em obras literárias, cinematográficas e narrativas orais, trazendo muitas vezes discussões sobre características identitárias. A Iara é presente em narrativas nas versões de folcloristas, como, por exemplo, o conto "A Iara do Rio Santana" no livro Visagens, Assombrações e Encantamentos da Amazônia (2019) de Walcyr Monteiro (1940-2019), em versões contemporâneas, como na série Cidade Invisível (2021), e na oralidade dos povos da região Amazônica.

O conto "La Yara. - version de Pará" no livro"Folk-lore Brésilien" (1889), de Frederico José de Santa-Anna Nery (1849-1902), conta a história de Iara através da oralidade popular de interioranos. Já "Lendas Brasileiras" (2015), versão do norte indígena e “Geografia dos Mitos Brasileiros” (2012), de Luís da Câmara Cascudo (1898-1986), descreve a origem da Iara no contexto histórico. São obras que compartilham características e padrões narrativos semelhantes, porém, com referenciais diferentes da lenda.

A narrativa oral é uma das formas mais antigas de preservação da cultura popular, mantendo mitos e lendas presentes dentre diferentes gerações. A autora do livro "Abecedário de personagens do folclore brasileiro" (2017) Januária Cristina Alves em entrevista para o site Guia do Estudante, ressalta que: "O folclore é a história da gente. Ele é a junção das nossas origens africanas, indígenas, europeias, orientais. É o jeito que o Brasil encontrou de contar a nossa história, tem tudo a ver com a nossa identidade" (2021) ${ }^{4}$. A Iara dos rios amazônicos possui algumas características distintas entre as histórias contadas pela região, resultado dos processos identitários dos povos, sendo conhecida por vezes como Iara, Mãe D'água ou Sereia.

A escritora argentina Rosalba Campra, em seu livro "Em los dobleces de la realidad: Exploraciones Narrativas" (2019), explora as narrativas de criaturas insólitas presentes na literatura fantástica, uma delas é nosso objeto de estudo, a sereia. A autora aborda no segundo capítulo Las sirenas, lo fantástico, y otros casilleros de la realidad, uma sistematização das sereias, algo que chama sua atenção desde a infância, analisando-as a partir de seus significados na literatura e suas representações iconográficas. Observa-se a origem das sereias como:

\footnotetext{
${ }^{4}$ Fonte: https://guiadoestudante.abril.com.br/dica-cultural/cidade-invisivel-revive-o-folclore-brasileiro/ Acesso em 06/10/2021.
} 
En su origen, iconografía y literatura representan a la sirena como un ave con torso y rostro de mujer; posteriormente su figura canónica será la de una mujer cuyo cuerpo en su parte inferior es el de un pez. En una y otra forma, se trata siempre de la seducción de una femineidad en la que sobreviven resabios animales. (CAMPRA, 2019, p.34) ${ }^{5}$

Dessa forma, a autora faz recortes das características desses seres insólitos de diferentes lugares, culturas e narrativas, formando um conjunto de elementos que se correlacionam e abrem espaço para estratégias de análises metodológicas de interpretação desse objeto de estudo. Nota-se que a estudiosa Campra destaca as sereias como:

[...] la sirena se define como tal en cuanto forma parte de la cohorte fabulosa de los híbridos femeninos (a la que pertenecen también categorías como las arpías o las esfinges, e individuos únicos en su especie, como por ejemplo Melusina, mitad mujer y mitad serpiente), pero su característica esencial es el canto, o más bien, el poder letal de ese canto. (CAMPRA, 2019, p.34) ${ }^{6}$

A Iara é um ser de versões e possibilidades, retratadas em contos, ilustrações, poemas, animações, séries e muitos outros meios. Esse ser insólito se destaca por sua pluralidade em diferentes obras. Inúmeros autores brasileiros representam em suas obras diferentes releituras da encantadora e perigosa Iara. Flávio Garcia afirma que "[...] o termo insólito aparece, por vezes, significando uma categoria ficcional comum a variados gêneros literários, sendo, desse modo, um aspecto intrínseco às estratégias de construção narrativa" (2012, p. 14).

O autor Câmara Cascudo em seu livro "Lendas Brasileiras" (2015), que relata as lendas específicas de cada região do país, na parte dedicada às lendas da região norte é apresentada "A lenda da Iara”, neste conto a sereia possui características indígenas, baseado no trecho a seguir:

Deitada sobre a branca areia do igarapé, brincando com os matupiris, que lhe passam sobre o corpo meio oculto pela corrente que se dirige para o igapó, uma linda tapuia canta à sombra dos jauaris, sacudindo os longos e

\footnotetext{
${ }^{5}$ Tradução nossa. Originalmente, a iconografia e a literatura representam a sereia como um pássaro com o torso e o rosto de uma mulher; mais tarde sua figura canônica será a de uma mulher cujo corpo na parte inferior é o de um peixe. De uma forma ou de outra, é sempre a sedução de uma feminilidade na qual sobrevivem os traços animais.

${ }^{6}$ Tradução nossa. a sereia é definida como tal na medida em que faz parte da fabulosa coorte de fêmeas híbridas (às quais também pertencem categorias como harpias ou esfinges, e indivíduos únicos de sua espécie, como Melusina, metade mulher e metade cobra). característica é a música, ou melhor, o poder letal dessa música.
} 
negros cabelos, tão negros como seus grandes olhos. (CASCUDO, 2015, p.07).

Já em seu outro livro "Contos tradicionais do Brasil (2014), retrata a Iara de aspectos europeus, conforme pode ser observado na seguinte sentença: "Numa ponta de pedra apareceu uma moça bonita como um anjo do céu, cabelo louro, olhos azuis e branca como uma estrangeira." (p.68). Dessa forma, é possível perceber a variedade de narrativas ao redor do Brasil envolvendo um mesmo ser.

Santa-Anna Nery no conto "La Yara. - version de Pará", apresentado no capítulo 10 do livro "Folk-lore Brésilien" (1889), traz os relatos de um antigo Comandante sobre a Iara do Pará, em que conta sobre a morte do jovem Januário na Província do Pará no ano 18. A história gira em torno da maldição da Iara, em que rapazes e noivos vivem ameaçados de serem vítimas dela. Assim que Januário fica noivo de Mundica, começa a ter experiências sobrenaturais na beira dos igarapés. Para Nery a Iara é:

-La Yara est une femme étrangement belle; quiconque la voit ne peut plus s'en détacher; de près ou de loin, il la voit constamment, il se sent pris pour elle d'une passion sans trève, et il se livre inconsciemment à une joie bruyante et délirante. Cet accès dure jusqu'à ce qu'il la revoie réellement, telle qu'il l'a aperçue la première fois, et alors il se jette à l'eau dans le même endroit où elle lui est apparue d'abord, fascinatrice et séduisante. Il sent ce désir intense de se jeter à l'eau, comme si c'était là le seul moyen d'éteindre les flammes d'amour qui le dévorent. (NERY, 1889, p. 107 - 108) ${ }^{7}$

Já no conto "La Yara. - Version de manáos" mostrado no capítulo 11 do mesmo livro, apesar de possuir um vocabulário indígena, a Iara mostrada no conto possui características europeias, com cabelos loiros e olhos verdes. Segundo Nery verifica-se que:

Comme elle était belle, mère I Comme était belle la femme qui s'y trouvait ! Elle était assise sur le bord de la rivière. Elle avait les cheveux blonds: comme s'ils étaient en or, attachés par des fleurs de mururé, et elle chantait,

\footnotetext{
7 Tradução Nossa: A Yara é uma mulher estranhamente bonita; quem o vê não pode mais se separar dele; perto ou longe, ele a vê constantemente, ele se sente tomado por uma paixão implacável por ela e inconscientemente se entrega a uma alegria ruidosa e delirante. Esse ataque dura até que ele realmente a veja novamente, como a viu pela primeira vez, e então ele se joga na água no mesmo lugar onde ela lhe apareceu pela primeira vez, fascinante e atraente. Sente um desejo intenso de mergulhar, como se fosse a única forma de extinguir as chamas do amor que o devoram.
} 
elle chantait...comme je n'ai jamais entendu chanter... (NERY, 1889, p. 152$)^{8}$

O autor Walcyr Monteiro, em sua ilustração do livro "Visagens, Assombrações e Encantamentos da Amazônia" (2019), retrata Iara apenas como uma linda moça com uma luz na testa, descrito da seguinte frase: "Raimundo não sabe explicar o que mais o atraía: se a beleza de seu corpo ou a luz que trazia na testa. Mas, segundo afirma, foi para segurar a luz que se jogou em cima da moça desnuda.” (p. 19). A narrativa não define as características da Iara, dando ao leitor uma atiçada na imaginação e na interpretação.

Percebe-se que nas diversas versões desses autores, a lenda é narrada de maneira heterogênea, mesmo dentro da mesma região. Um mesmo ser insólito, replicado com diferentes faces, predominando apenas seu canto indescritível e beleza extraordinária.

Uma representação contemporânea da Iara foi exibida na série nacional Cidade Invisível (2021), produzida pela Netflix, possui sete episódios na primeira temporada, e retrata o submundo de personagens do folclore brasileiro na cidade do Rio de Janeiro. A série foi criada pelo diretor brasileiro Carlos Saldanha, com base e Consultoria no livro “Abecedário de personagens do folclore brasileiro" (Sesc/FTD) de Januária Cristina Alves.

Em entrevista ao site Uol, o diretor Carlos Saldanha diz que "Queria dar uma roupagem contemporânea, nova, falar de folclore, mas não ser uma coisa infantil" (2021 $\left.{ }^{9}\right)$, sendo assim, o objetivo da série é reconectar os brasileiros ao folclore sob uma nova visão e mostrar para o mundo alguns exemplos da nossa cultura.

Portanto, torna-se relevante o estudo da adaptação da história da sereia, sob uma visão contemporânea em relação às diversas caracterizações existentes, tendo como foco a personagem Camila (Iara), elucidando sua pluralidade entre as regiões brasileiras.

\section{Iara na literatura}

De acordo com o folclorista e antropólogo Câmara Cascudo, no livro "Geografia dos Mitos Brasileiros” (2012), no século XVI e XVII não havia registros da existência de uma lenda sobre a Iara, as lendas indígenas da época mencionam apenas o homem marinho,

\footnotetext{
${ }^{8}$ Tradução Nossa: Como ela era linda, mãe, como era bonita a mulher que estava ali! Ela estava sentada na beira do rio. Ela tinha cabelos loiros: como se fossem dourados, amarrados com flores de parede, e ela estava cantando, ela estava cantando ... como se eu nunca os tivesse ouvido cantar ...

${ }^{9}$ Fonte: https://www.uol.com.br/splash/noticias/2021/02/05/por-que-carlos-saldanha-deixou-a-animacao-delado-por-cidade-invisivel.amp.htm Acesso em 06/10/2021
} 
nomeado de Ipupiara, uma criatura assustadora que habita o fundo das águas, afogador de índios. Os portugueses influenciaram a personificação da Iara, ao deduzirem arbitrariamente que esse fantasma marítimo seria uma sereia.

Cascudo expõe que na mitologia grega as Oceânides e Nereidas são ninfas que representavam a beleza marinha e ajudam os marinheiros em perigo. Também existiam as sereias dos gregos e romanos, descritas como parte mulher e parte pássaro, originalmente, eram moças sentadas na praia, cantando. Apenas no século XV a sereia com parte mulher e parte peixe aparece nas fábulas ibéricas, que seria a junção das Oceânides e sereias.

Os portugueses possuíam o mito da Moura Encantada, um ser que cantava maravilhosamente em fontes, rios e córregos, pedindo para os homens quebrarem seu encanto e em troca lhes daria riqueza e seria uma esposa boa e fiel. Com tudo isso, ocorreu a confluência entre as Mouras e as Oceânides e Nereidas clássicas, tornando-se em sereia e sendo popularizada ao redor do mundo pelos navegantes portugueses.

Ainda segundo Câmara Cascudo, ocorreu uma distorção da lenda do Ipupiara pelos portugueses, em que suas referências europeias de sereias modificaram e silenciaram a lenda indígena, resultando na criação da Mãe D'água. Aparentemente, é criada a primeira versão da Iara no Brasil, visto que tal representação não existia na cultura indígena, marcando a imaginação popular com a idealização de uma linda sereia de cabelos louros e olhos verdes, que vivia no fundo dos rios. Dos selvagens à beleza exótica, o Ipupiara deu lugar a Iara. Já para Cascudo:

\begin{abstract}
A Iara que mora num palácio no fundo dos rios é uma tradição dos brancos e que vicejou rapidamente no cenário bárbaro do Brasil colonial. O barão de Santana Neri (Folklore Brésilien, Paris, 1889, pp. 44/152) falando das Yaras descreve uma mulher branca, de olhos verdes e cabeleira loura, em ambas as versões do Pará e Amazonas. As crenças locais de forma alguma possuíam essa variante. Demais, é preciso notar, a beleza física da Iara, seus métodos de sedução, a forma de sua residência submersa, denunciam um elemento alienígena que conduziu o mito e o espalhou sob as águas do setentrião brasileiro. (CASCUDO, 2012, p. 139).
\end{abstract}

O Ipupiara é um ser aquático que assombra o imaginário dos indígenas com sua aparência e seus trejeitos, o historiador Pero de Magalhães Gandavo (1579), em seu livro História da Província de Santa Cruz (1576), conta a história de um fidalgo português que matou o Ipupiara no litoral de São Paulo, em 1564. A criatura é descrita como um demônio d'água, um monstro enorme com andar desajeitado sobre suas barbatanas e o corpo coberto 
por pelos, o oposto de toda a beleza incubida a Iara. Dois seres insólitos que tem como objetivo tirar vidas humanas, porém, com diferentes meios para isso.

O Ipupiara é um monstro bruto e selvagem. Ele come suas vítimas e volta para as águas, no entanto a Iara é a representação de beleza exótica. Pois, trata-se de uma sereia, com táticas diferentes de fazer vítimas, ela cativa para matar, levando consigo para o fundo das águas os homens enganados.

Entre as crenças africanas existe a divindade Iemanjá que tem relação direta com as águas, mãe d'água idolatrada por aqueles que acreditam em suas potencialidades como ser insólito. Segundo Câmara Cascudo, em seu livro Geografia dos mitos brasileiros (2012), foi afirmado por alguns negros ter aspectos de sereia.

\section{1 “A Iara do Rio Santana” de Walcyr Monteiro.}

Walcyr Monteiro (1940-2019) nasceu em 27 de janeiro de 1940, na cidade de Belém do Pará. Era escritor, jornalista, sociólogo, ufólogo, acadêmico das letras. Walcyr deixou um vasto legado cultural voltado para a preservação e enaltecimento do folclore e manifestações populares brasileiras. Seu livro "Visagens e Assombrações de Belém" narra histórias populares de lugares específicos da cidade de Belém, fazendo o registro de lendas e mitos que permeiam a cidade, mostrando assim uma outra visão da cidade. Através dessa obra o escritor pode guardar relatos da tradição oral que geralmente são esquecidos com o passar do tempo, além disso, serviu como base para um longa-metragem intitulado de 'Lendas Amazônicas' (1998) e um curta-metragem 'Visagem' (2006).

Walcyr também publicou uma série chamada "Visagens, Assombrações e Encantamentos da Amazônia", publicada desde 1997, a cada ano um exemplar desde então. As coleções reúnem cinco livros em cada volume, e cada publicação apresenta cinco narrativas diferentes. Essas histórias foram coletadas pelo autor em suas pesquisas ao longo da região amazônica, fazendo registros de crenças, lendas, mitos, visagens, assombrações e encantamentos.

Dentre essas coleções está o texto abordado neste artigo, intitulado "Iara do Rio Santana", publicado em 2019, volume 2, pela editora Três C. Produzido a partir dos registros de Walcyr Monteiro em suas pesquisas sobre seres fantásticos da região norte, que fazem parte do imaginário popular. 
A lenda da Iara do Rio Santana é apresentada através dos relatos de Raimundo Martins Maia, o personagem principal que teve contato com a Iara, e o relato de parentes e amigos que o encontraram depois. $\mathrm{O}$ encontro com a Iara foi uma experiência sobrenatural para Raimundo, relatando sentimentos e sensações incomuns. Ao surgir uma luz muito brilhante que captou a atenção de Raimundo, seus olhos e seu corpo eram puxados para a bela mulher que saía do rio, não raciocinando ao pular dentro do rio sem saber nadar.

Após pular dentro do rio atrás da Iara, Raimundo é encontrado desacordado, quatro dias depois, na beira do igarapé, afluente do Rio Santana, sendo levado a lugares em que haviam manifestações mediúnicas, somente voltando a consciência quando o defumavam com casca de umiri. Ao abrir os olhos enxerga de novo a moça do Rio Santana, pulando em direção a visagem para agarrá-la, só que ela fugirá e ele foi atrás, tendo que ser amarrado novamente.

Raimundo passou por vários lugares até chegar no Estado do Maranhão onde foi curado, voltando ao seu normal, porém, não lembrando de nada do que havia acontecido depois que pulou no rio pela primeira vez. Contudo, Raimundo afirma não conseguir chegar perto de rio ou igarapé, especialmente em noites de lua cheia, devido a grande vontade de pular no rio de encontro a Iara.

Esse conto apresenta características distintas de outras narrativas literárias e orais já citadas. A história é narrada pelo próprio personagem desse encontro com a Iara, geralmente as narrativas sobre essa personagem são contadas por terceiros. Outra particularidade desse conto é que não há muitas descrições sobre a moça que emerge das águas, a narrativa não define os aspectos físicos da Iara, se ela utiliza seu canto hipnotizante ou se possui cauda de peixe. Apesar da ausência desses atributos que representam a Iara de maneira geral, o conto consegue cativar o leitor e a natureza desse ser insólito ainda é enaltecida ao atrair os homens para o fundo das águas com sua beleza.

\section{Iara na narrativa oral}

A narrativa oral é fundamental para preservação da herança cultural dos povos, através das histórias contadas oralmente, as memórias e conhecimentos de cada grupo e região perpetuam durante anos. É comum que ao longo dos anos as narrativas sofram modificações, visto que cada narrador/contador de histórias pode remodelar características 
da narrativa, características essas que têm ligação aos processos identitários vividos pelos povos.

A literatura oral e a vida cotidiana se entrelaçam no ato de narrar histórias, "[...] é nos textos orais que encontramos a memória histórica retrabalhada pela ficção narrativa." (CAVIGNAC; MOTTA, p. 12, 2004). A lenda da Iara é um clássico dentro da cultura brasileira, todavia, é nas regiões amazonenses que a Iara é crença entre as pessoas, e geralmente, é nessas regiões interioranas que a história vale mais que o fato, devido a grande credibilidade que os seres sobrenaturais têm. Crer na Iara é ter medo e precaução, evitando rios e igarapés em noites de lua cheia.

A lenda da Iara é um exemplo de história modificada pela oralidade de diferentes regiões, apresentando sereias que se distinguem pela: origem, indígena ou europeia; o modo de agir, levando a vítima para o fundo do rio ou se casando com ele, prometendo riquezas; e pela aparência, podendo ser loira dos olhos verdes, ou morena dos olhos e cabelos pretos. Todas essas características diversas contribuem para que as obras ficcionais sobre a Iara sejam diversificadas no modo de narrar sua história.

\subsection{Iara: terror e horror na Amazônia}

A região amazônica tem um grande acervo em mitos e lendas de horror, que são derivados de elementos da natureza. Os pioneiros desta região foram responsáveis por difundir mitos e lendas regionais, contados de boca a boca em rodas de conversas como forma de explicação ao absurdo, e também, de preservação da literatura oral da região, pois os mitos e lendas

[...] são consequência das buscas de sentidos da natureza pelos seres humanos. Os mitos são uma espécie de linguagem para descreverem os acontecimentos dos arredores e eram transmitidos de gerações para gerações pelas cotações de estórias, fábulas e narrativas. (CORDOVIL, 2020, p. 174)

Histórias contadas nessas rodas de conversa tendem a ser atraentes e instigantes, prendendo a atenção dos ouvintes, o que nos leva ao gênero mais recorrente nesses casos, o horror. As histórias regionais geralmente trazem em si personagens insólitos que são símbolos de horror, punem aqueles que entram em seu caminho, seja por vingança, maldição ou proteção. As razões por trás do horror nos atos dos personagens, regularmente, provocam 
afeição dos ouvintes, tornando-se justificáveis ações violentas ou de má fé. Carroll afirma que as características das obras de horror apresentam:

[...] Como as obras de suspense, as obras de horror são concebidas para provocar certo tipo de afeto. Vou presumir que esse é um estado emocional cuja emoção chamo de horror artístico. Assim, pode-se esperar situar o gênero do horror, em parte, por meio de uma especificação do horror artístico, ou seja, da emoção que as obras desse tipo são destinadas a gerar. Os membros do gênero do horror serão identificados como narrativas e/ou imagens (no caso das belas-artes, do cinema etc.) que têm como base provocar o afeto de horror no público. (CARROLL, 1999, p.30)

A Iara é um símbolo de terror e horror na região amazônica, para aqueles que acreditam em sua lenda. $\mathrm{O}$ terror se faz presente na vida das pessoas que temem o encontro com ela, visto que seu canto e beleza enfeitiçam os homens, caindo em sua armadilha mortal. Isso é visto nos contos de Nery e de Câmara Cascudo, em que os avisos são constantes quando se trata de evitar a Iara, sendo notável o terror presente na vida das pessoas. Para Cascudo:

Cai a noite, as rosas e os jasmins saem dos cornos dourados e se espalham pelo horizonte, e ela canta e canta sempre; porém o moço tapuio que passa não se anima a procurar a fonte do igarapé. Ela canta e ele ouve; porém, comovido, foge repetindo: - "É bela, porém é a morte... é a Iara."(CASCUDO, p. 07, 2015)

Ao se tornar uma vítima da Iara, caso consiga voltar com vida, o homem passa a ser aterrorizado pelo encanto da sereia, convivendo com o horror do acontecido, mas sem lembrar de nada. As pessoas ao seu redor também vivenciam esse horror, olhando de fora o que acontece com a vítima, e sem poder fazer nada. Quando o homem consegue escapar da morte no fundo do rio, ele volta para a superfície com sequelas da experiência sobrenatural. Assim, é relatado no conto de Walcyr Monteiro, em que o personagem principal, Raimundo, volta do fundo do rio com comportamentos estranhos, surtos repentinos, e sem estar em sua razão. Tais comportamentos são os resultados do pós-sobrenatural, forçando os familiares e amigos a vivenciarem o horror depois do contato com o insólito. Como vemos a seguir neste trecho do conto:

Reunidos parentes e amigos, chegaram à conclusão que deveriam levá-lo para a casa de uma "experiente". Foi escolhida, por suas qualidades e fama de infalível, a "experiente" Mangabeira Dona Flor. [...] No meio da viagem, 
defronte à Ilha do Bode, Raimundo pulou n'água. É necessário salientar que não sabia nadar. Pularam atrás dele e, depois de muito custo, conseguiram jogar uma tarrafa, amarrando-o fortemente. E nestas condições Raimundo fez o resto da viagem até o porto de Dona Flor (MONTEIRO, p. 21, 2019)

O comportamento e as esquisitices que acontecem com Raimundo vão além do explicável, as pessoas passam a assumir o insólito como forma de resposta para aquilo que está acontecendo com ele. Os parentes e amigos de Raimundo tentam curar o sobrenatural com a ajuda do espiritual, o que indica o quão aterrorizante e perturbadoras são as "marcas" deixadas por Iara em suas vítimas.

\section{Iara nas narrativas cinematográficas}

Nas narrativas cinematográficas existe a possibilidade de trabalhar uma mesma história de inúmeras formas, ou seja, o universo cinematográfico é capaz de ampliar os horizontes de um personagem e movê-lo no tempo, no espaço, modificar sua aparência e enredo.

A Iara possui diversas representações cinematográficas, como por exemplo, no seriado de televisão "O Sítio do Picapau Amarelo" (2001 a 2007), baseada na série de livros sobre literatura fantástica de Monteiro Lobato (1882-1948) transmitido pela Rede Globo. Ao longo do seriado a Iara é interpretada por quatro atrizes. A personagem muda as suas características de acordo com cada atriz, às vezes possui pernas e outra cauda, às vezes é loira de olhos claros e em outra é morena de cabelos escuros. A característica que permanece igual em todas é o canto sedutor da Iara que hipnotiza as suas vítimas curiosas.

Outra obra cinematográfica que retratou a Iara foi a novela "Caminhos do Coração" (2008), a sereia Iara era interpretada por Suyane Moreira, uma linda mulher, de pele morena, cabelos longos e traços indígenas. A sereia representada na novela possui cauda e a habilidade de transformá-la em pernas e o canto encantador e perigoso, sendo chamada de bruxa das águas por alguns personagens.

A mais recente adaptação cinematográfica foi a série nacional da Netflix "Cidade Invisível” (2020) retrata o folclore brasileiro através de uma releitura das narrativas de alguns mitos e lendas que compõem a nossa cultura popular. $\mathrm{O}$ rompimento das narrativas ocorre na explicação da origem dessas entidades míticas e na ambientação em que elas estão inseridas, provocando uma nova configuração para o surgimento de lendas que estão presentes na herança cultural, advindas da oralidade dos antepassados. 
A personagem Camila traz uma nova interpretação para a Iara. Diferentemente, das obras literárias que descrevem a sereia com características indígenas e europeias, nessa adaptação a Iara é alta, magra, negra, com cabelos longos e trançados. Além disso, a sereia pode migrar entre o mundo insólito e o mundo racional, assim como outras figuras do folclore, como a Cuca, Saci, Curupira e o Boto Cor-de-rosa.

A Iara que até então era retratada por muitos apenas como uma criatura das águas, na série, ela vive como uma humana e exerce a profissão de cantora em um bar. Também possui uma outra versão de origem, no início do episódio três "Eles estão entre nós", da primeira temporada, Camila revela: "Mãe d'água, Iara, sereia, cada um dá um nome [...] Quem eu amava acabou me matando. Mas, quando a água do mar me devolveu a vida, passei a levar os homens para a morte. É a minha maldição" (2020, 3 min).

Apesar de possuir uma leitura diferente e uma performance moderna, a essência da lenda da Iara ainda é mantida. O canto e a beleza hipnotizante, continuam sendo seus atributos para atrair os homens para a morte. Dessa forma, essa representação contemporânea permite que as novas gerações tenham acesso às lendas e mitos que fazem parte da história do país.

Embora a série busque enaltecer a cultura brasileira, a série recebeu críticas direcionadas principalmente para a ambientação, rompimento das narrativas tradicionais e a falta de personagens ou consultores indígenas. A série provocou estranhamentos por se passar na cidade do Rio de Janeiro, apesar de retratar lendas que fazem parte de outras regiões do país.

Em entrevista ao site de notícias diárias Catraca Livre, a ativista e comunicadora Alice Pataxó, expressa: "Não existe protagonismo indígena e muito menos somos citados no meio disso. Algo que nos pertence! A série é um outro jeito da dramaturgia estar nos apagando da nossa própria história” $(2021)^{10}$. Dessa forma, as principais críticas sobre a série é a falta de representatividade das comunidades amazônicas, já que essas entidades do folclore fazem parte da cultura indígena passada de geração em geração.

\section{Considerações Finais}

Ao decorrer deste estudo pudemos perceber que a Iara é um ser plurifacetado desde suas origens até os elementos e narrativas que a caracterizam, podendo ser representada de

\footnotetext{
${ }^{10}$ Fonte: https://catracalivre.com.br/entretenimento/netflix-cidade-invisivel-alcanca-o-sucesso-mas-esquecedo-protagonismo-indigena/ Acesso em: 06/10/2021.
} 
diferentes formas dentro de uma mesma região e em vários gêneros literários e cinematográficos. Suas origens são difundidas pelas regiões trazendo aspectos europeus, mas também aspectos indígenas, transparecendo tais características em seus contos por meio da descrição de sua beleza. Parte do folclore brasileiro, essa personagem é de conhecimento popular sendo apresentada em livros sobre lendas brasileiras, mais derivadas às crianças, porém é nas narrativas orais e literárias da região amazônica que se sobressai a Iara como esse ser sobrenatural que enfeitiça, causa terror e horror, levando suas vítimas para o fundo do rio.

O conto "A Iara do Rio Santana" de Walcyr Monteiro narra como a força sobrenatural da Iara age sobre os homens que conseguem sobreviver ao fundo do rio, no caso Raimundo. Mesmo sobrevivendo Raimundo não volta por inteiro daquele rio, sua racionalidade fica presa lá, agindo de forma estranha para seus amigos e parentes. Esse conto se passa na região norte, estendendo-se um pouco para o nordeste devido a busca pela recuperação de Raimundo.

A Iara causa terror às pessoas que creem na sua existência, visto que temem o encontro com ela nos rios e igarapés, principalmente em noites de lua cheia. Na região amazônica, para aqueles que acreditam em sua lenda, a Iara é um símbolo de terror e horror. Pessoas que vivem próximas a rios e igarapés convivem com o terror constante do encontro com a sereia. O horror vem por acontecer quando se tem contato com esse ser sobrenatural, a vítima é encantada e, contraditoriamente, passa a desfrutar o horror do encontro.

A complexidade de um ser insólito como a Iara se encontra nesses mínimos detalhes, sua origem, sua aparência, suas ações sobre as vítimas, quais os efeitos que ela causa sobre o homem enfeitiçado. Vemos que não se trata somente de um monstro sanguinário, mas sim de um ser que reúne características que criam histórias que são narradas pelos livros e pelas bocas das pessoas mais conhecedoras dessas lendas das comunidades.

\section{Referências}

CABRAL, Cleber Araújo; TAVARES, Enéias; CORDOVIL, Suellen. Monstruosidades do Fantástico Brasileiro. Dialogarts. $1^{\text {a }}$ Edição digital. Rio de Janeiro, 2020.

CAMPRA, Rosalba. Los dobleces de la realidad. Exploraciones narrativas. León: Editorial EOLAS, 2019.

CATRACA LIVRE. Netflix: "Cidade Invisível". Disponível em: $<$ https://catracalivre.com.br/entretenimento/netflix-cidade-invisivel-alcanca-o-sucesso- 
mas-esquece-do-protagonismo-indigena/> Acesso em: 24 fev 2021.

CARROLL, Noël. A filosofia do horror ou paradoxos do coração. Campinas: Papirus, 1999. 319 p. (trad. Roberto Leal Ferreira)

CASCUDO, Luís da Câmara. Dicionário do Folclore Brasileiro. Rio de Janeiro: Edições de Ouro, 1969.

CASCUDO, Luís da Câmara. Lendas Brasileiras. Global Editora. $1^{\text {a }}$ Edição digital. São Paulo, 2015.

CAVIGNAC, J; MOTTA, A. Retóricas do olhar e tramas da narrativa. XXVIII Encontro Anual da ANPOCS - Seminário temático n. 70, 2004.

FANTÁSTICO - modo - Dicionário Digital do Insólito Ficcional - e-DDIF. Disponível em: <http://www.insolitoficcional.uerj.br/f/fantastico-modo/>. Acesso em: 07 abr. 2021.

GUIA DO ESTUDANTE. Cidade Invisível revive o folclore brasileiro. Disponível em:<https://guiadoestudante.abril.com.br/dica-cultural/cidade-invisivel-revive-o-folclorebrasileiro/> Acesso em: 11 abr 2021

INSÓLITO FICCIONAL - Dicionário Digital do Insólito Ficcional - e-DDIF. Disponível em: <http://www.insolitoficcional.uerj.br/i/insolito-ficcional/>. Acesso em: 07 abr. 2021.

MONTEIRO, Walcyr. Visagens, Assombrações e Encantamentos da Amazônia. V. 02 Belém: 3C Editora, 2019.

NERY, Frederico de Santa-Anna. Folk-lore Brésilien - Poésie populaire - Contes et Légendes - Fables et Mythes - Poésie, Musique, Danses et Croyances des indies. Paris: Perrin et cie Libraires, 1889.

Artigo recebido em: 09.10.2021

Artigo aceito para publicar em: 14.12.2021 